\title{
Government Ability, Bank-Specific Factors and Profitability: An Insight from Banking Sector of Vietnam
}

\author{
Van Chien Nguyen*, Thu Dau Mot University,Vietnam.Email: chiennv@tdmu.edu.vn \& chienmpp3@gmail.com \\ Thu Thuy Nguyen, Academy of Finance, Vietnam. Email: nguyenthuthuy@hvtc.edu.vn \\ Huu Tinh Nguyen, Thu Dau Mot University,Vietnam.Email: tinhnh@tdmu.edu.vn
}

\begin{abstract}
To the best of our knowledge, a very few studies have focused on the effects of government ability on bank performance in developing and emerging countries. The aim of this work is to study the impact of government ability, bank-specific factors on profitability in the banking system in Vietnam. Using a panel data analysis in the period over 2014-2018, the study analyzes based on the methods of fixed, random effects, and pooled ordinary least squares. Data were collected from Vietnam's Stock Exchange, General Statistics Office, and Worldwide Governance Indicators. Our results demonstrate that government ability has negatively affected bank efficiency while economic growth will not affect bank efficiency. In addition, the prime bank-specific factors that can significantly impact on bank efficiency are non-performing loan, loan-to-deposit ratio, loan loss reserves. A bank with a higher loan-to-deposit ratio can positively impact on the probability of a bank. In contrast to the risk, a bank with a greater risk as well as a higher level in non-performing loan in operation will negatively impact on its efficiency.
\end{abstract}

Keywords--- Bank-specific Factors, Control of Corruption, Economic Growth, Panel.

JEL Classifications codes--- G21, G24, G32, G38.

\section{Introduction}

Banking system has been considered as a very important organization in promoting financial market in each country. This sector has greatly played an important role in production, consumption, and as the lifeblood of the economy. Theoretical model pointed out a healthy bank can support more lending and reduce transaction fees. If the bank has such a high cost of transactions such as banking fees, customer service, and overhead that will challenge its performance (Nguyen, 2020).

The critical view that the bank performance has been impacted by a number of bank-specific, industry-specific and macroeconomic factors. Previous studies of Guo et al. (2019), Fang et al. (2019), Ekinci \& Poyraz (2019), Martins et al. (2019), Sohel Azad et al. (2019), Nguyen \& Do (2020), Brandao-Marques et al. (2020) show that these factors can affect bank performance. As shown by Martins et al. (2019), bank-specific factors in agreement with credit risk, liquidity risk, and operational efficiency, total loans growth, cost of opportunity and implicit interest payments can frequently explain bank efficiency. It is further discussed that the bank's market power, GDP and interest rate volatility can have a significant effect on its performance.

In the case of Vietnam, banking system has contributed a large role in development of financial system and support to the economic growth at approximately 7 per cent since in 1986 (Nguyen \& Tran, 2013; Nguyen, 2020; Van, 2020). However, the banking system has faced many difficulties regarding bad debts and profit loss in the period of 2012 - 2016. Accordingly, the Resolution 42/2017/QH14 was created by National Assembly in order to solve bad debts in the financial institutions. The Prime minister's Decision 1058/QD-TTg was also approved a plan to restructure credit institutions associated with the problems of bad debts in the 2016-2020 period.

In the context of institutional transition in Vietnam, the government that can create, enforce, and apply laws, and often negotiate conflict, make policy to support financial system. To the best of our knowledge, a very few studies have focused on analyzing how government ability can affect bank efficiency in developing and emerging economies, especially in the low-middle income economies. Therefore, the objective of this study aims at fulfilling this gap by examining the relationship between government ability and bank efficiency. The purpose of the study is also to find out the correlation between bank-specific, macroeconomic factors and the profitability of a bank in the case of Vietnam over the time period of 2014 to 2018. 
The remainder structure of the study is organized as follows: Section 2 discusses the literature review. Section 3 describes the data and methodology used in this study. The empirical results and discussion are presented in Section 4 and Section 5. Section 6 covers the conclusion and implications.

\section{Literature Review}

Banking sector has been known as the heart of the financial market which has greatly contributed an important role in attracting deposits to provide credits to borrowers, other services to customers and enhancing the economic development. A large numerous studies examining the determinants of bank efficiency have been focused on the developing and developed countries. Theoretical frameworks correlated to bank efficiency such as theory of Rashid and Jabeen (2016), Ho et al. (2016), Guo et al. (2019), Fang et al. (2019), Ekinci \& Poyraz (2019), BrandaoMarques et al. (2020). These previous studies aim to analyze the bank-specific, macroeconomic, and industryspecific factors that can impact the efficiency of a bank in the specific countries.

A very few studies have focused on the effect of government ability on bank efficiency in both developing and developed countries. It reports that fulfilling this gap by examining the correlation between both variables has importantly become to find out how the government can support the bank in operation. In general, political institutions include the organizations in a specific government that can create, enforce, and apply laws. They often negotiate conflict, make policy to support financial system, social systems and the economy, human lives quality. As observed in the recent study, Guo et al. (2019) study on government subsidies and institutions of market-supporting in China's SMEs. Guo et al. (2019) describe that financial slack in a firm can promote its performance. Further, investment in R\&D can partially moderate the link between financial slack and performance. The important finding indicates that the link between financial slack and investment in $R \& D$ will be declined in greater government subsidies, and the effect of R\&D investment on firm performance will be strengthened in a higher level of government subsidies and market supporting from institutions.

Further investigated, Ho et al. (2016) investigating the cross-country data in the $2000-2010$ period, it is evident that a government-owned bank under firm supervising does not underachieve a private-owned bank while this under low-powered supervising can underperform a government-owned bank. In addition, the promotion of monitoring under the permission of the political institutions and government can have major effects on bank's performance. Brandao-Marques et al. (2020) using an international sample of financial institutions and found that the support of government to the financial institutions via implicit or explicit guarantees can impact the readiness to accept risk by generating charter value or decreasing market discipline. More specifically, government support will be correlated with a higher level in risk taking by financial institutions. In addition, Brandao-Marques et al. (2020) also demonstrate that restricting the scope of activities in the financial institutions can make improvements to the relationship between support of government and bank risk accepting.

Following the approach in Ekinci \& Poyraz (2019), who examine the effect of credit risk on bank's efficiency by using a sample of 26 Turkish banks in the period of 2005 - 2017. The efficiency of a bank can be measured by either Return on Equity (ROE) or Return on Asset (ROA). In the results, there is a negative correlation between Non-Performing Loans (NPLs) and ROA as well as between NPLs and ROE. As suggested in Rashid and Jabeen (2016), using an unbalanced panel data covering in the 2006-2012 period, the regression results describe that factors as operating efficiency, reserves, overheads, deposits, and market concentration are significant in discussing profitability of banks. In addition, the effect of GDP, and interest rate of lending on efficiency is negative. The results also depict that enhancement in total management practices as well as a new standard in operating efficiency, financial risk administration will significantly contribute performance of a bank. Further discussed on the bank's performance, Fang et al. (2019) also suggest that size of bank, cost and profit efficiency, and particularly inflation will be found to be importantly associated with Chinese bank profitability. In addition, the positive effect of cost efficiency on efficiency is certainly greater in the case of a higher level of risk and more competition in the financial market.

Using 108 banks in the U.K, the U.S, and Germany covering in the period of 2010 - 2014, Martins et al. (2019) demonstrate that bank-specific factors in relation to credit risk, liquidity risk, and operational efficiency, total loans growth, cost of opportunity and implicit interest payments can frequently explain bank efficiency. In addition, the market power, GDP and interest rate volatility can also have a significant effect on performance. As shown by Sohel Azad et al. (2019) in a group of twenty countries and indicate that the fee in a bank is as a major factor that affects the efficiency of Islamic bank. In addition to loan to deposit ratio (LDR), a lower sensitivity to LDR may significantly contribute to a lower level in credit risk. In contrast, an over-reliance on income from fee may impact on the growth, bank's profitability in the long run. 


\section{Data and Methodology}

\subsection{Data}

The data used in the study is retrieved from the database of World Governance Indicators (WGI), General Office Statistics (GSO) of Ministry of Planning and Investment, and Ho Chi Minh City Stock Exchange (HOSE), Hanoi Stock Exchange (HNX). The data includes both domestic-owned commercial banks and foreign-owned commercial banks. Approximately 27 commercial banks used in this study has mainly represented for almost Vietnamese bank's assets. In addition, the data used in this study were collected in the period of time from 2014 to 2018 on a yearly basis, using Stata 15 software for analysis.

\subsection{Research Model}

According to the theoretical consideration, it is reported that this study will analyze based on the approach of panel data with pooled Ordinary Least Squares regression (OLS), which is more commonly named linear regression, further, fixed effect method (FEM), and random effect method (REM) are also concerned. The research model will be drew in the following Figure 1:

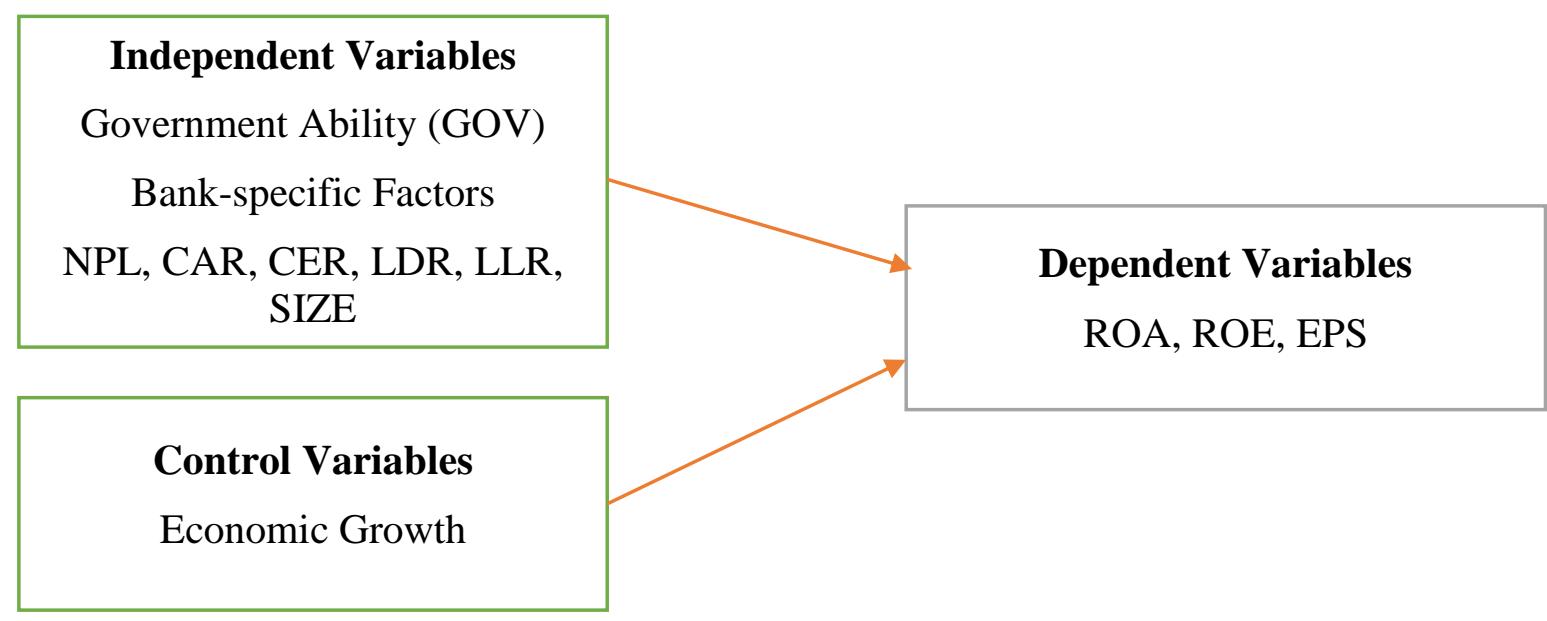

Figure 1: Research Model

In order to select the best model among Pooled OLS, FEM, and REM, we will investigate based the following Figure 2:

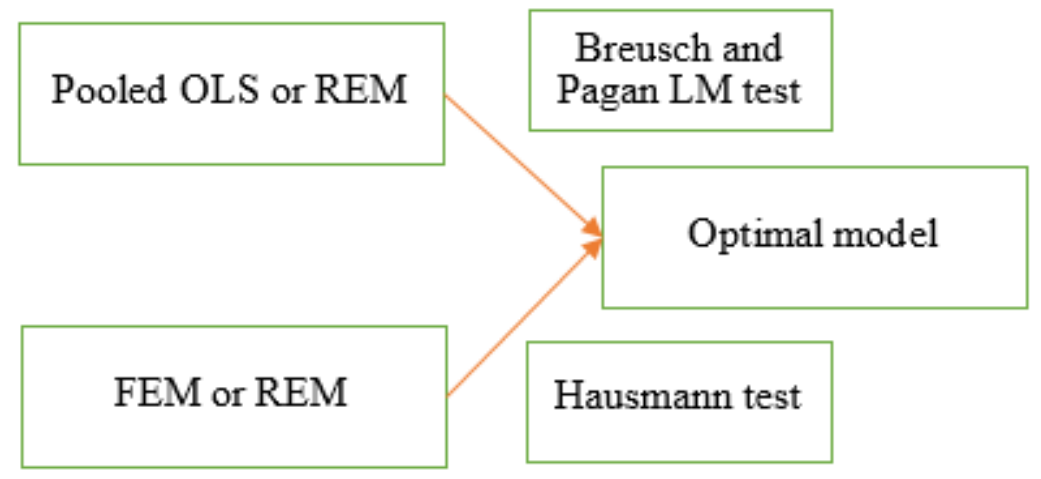

Figure 2: Model Selection

In order to discover the analysis of this relationship, we hypothesize the following model:

Where:

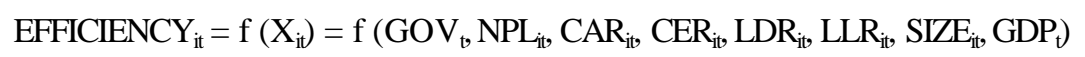

- EFFICIENCY ${ }_{i \mathrm{t}}$ is the independent variable; $\mathrm{i}$, and $\mathrm{t}$ are proxy for the bank $\mathrm{i}$ and time $\mathrm{t}$. This variable can be measured by ROA (return on assets), ROE (return on equity) or EPS (earnings per share), 
- $X_{i \mathrm{t}}$ indicates for the independent variable. It includes government ability (GOV), and bank-specific factors, economic growth (GDP). In addition, NPL, CAR, CER, LDR, LLR are abbreviated for non-performing loan, capital adequacy ratio, cost efficiency ratio, loan-to-deposit ratio, loan loss reserves. In the banking system, LDR is used to assess a bank's liquidity by comparing a bank's total loans to its total deposits for the same period. LLR is accounted for entries banks make to cover estimated losses on loans due to defaults and nonpayment.

In this study, we analyze based on FEM. In the theoretical framework, the equation for FEM is:

Where:

$$
Y_{i_{\mathrm{t}}}=\beta_{1} X_{i_{\mathrm{t}}}+\alpha_{i}+u_{i_{\mathrm{t}}} \quad(1.1)
$$

- $\alpha_{i}(i=1 \ldots . . n)$ is the unknown intercept for each bank (n bank-specific intercepts),

- $Y_{i t}$ is the explanatory variable; $\mathrm{i}$, and $\mathrm{t}$ denote for the bank $\mathrm{i}$ and time $\mathrm{t}$.

- $X_{i t}$ denotes an independent variable.

- $\beta_{1}$ is the coefficient for that explanatory variable,

- $u_{i \mathrm{t}}$ is the error term.

For REM, the assumption of REM is that the variation across entities is random and uncorrelated with the predictor or independent variables. The best advantage of random effects is that it can include time invariant variables. For FEM, these variables are absorbed by the intercept. In contrast, REM allows to generalize the inferences beyond the sample used in the model

Where:

$$
Y_{i \mathrm{t}}=\beta_{1} X_{i \mathrm{t}}+\alpha_{i}+u_{i \mathrm{t}}+\varepsilon_{\mathrm{it}}
$$

- $\alpha_{i}(i=1 \ldots . . n)$ is the unknown intercept for each bank (n bank -specific intercepts),

$-Y_{i t}$ is the explanatory variable; $i, t$ denote for the bank $\mathrm{i}$ and time $\mathrm{t}$.

- $X_{i t}$ denotes an independent variable.

- $\beta_{1}$ is the coefficient for that independent variable,

- $u_{i t}$ is the error term between entity error,

- $\varepsilon_{i t}$ is the error term within entity error.

\section{Results of Economic Modeling}

\subsection{Descriptive Statistics}

As shown by Worldwide Governance Indicators (WGI), the index of government ability measured by corruption control. It indicates that perceptions of the extent to which public power is acted for private gain, including both petty and grand forms of corruption, as well as capture of the government by elites and private interests. In the report, the index of government ability of Vietnam has gradually decreased in the period of $2014-2018$. This index has a range from 0 (lowest) to 100 (highest) rank). Figure 3 indicates that the best index for Vietnam was 40.87 in 2014 and 41.83 in 2018 while the worst index was 31.25 in 2017. It is further suggested that the government ability of Vietnam has been worse.

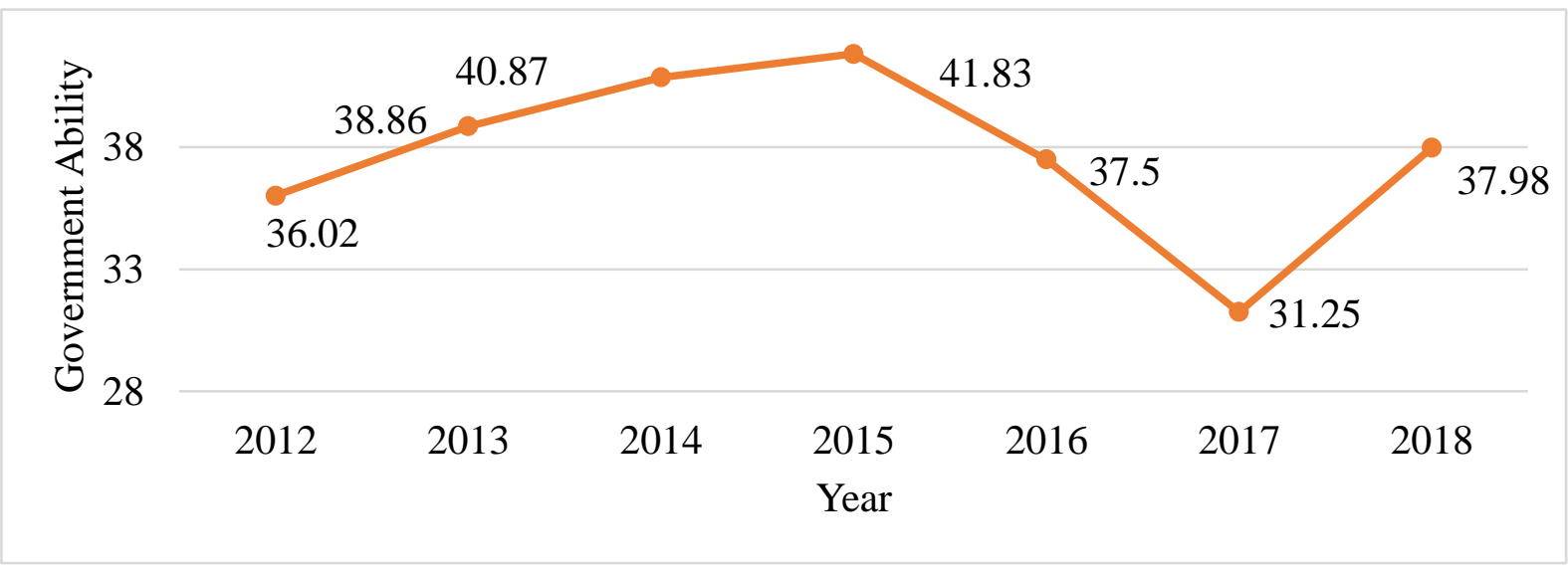

Source: WGI (2019)

Figure 3: Government Ability 
Table 1: Descriptive Statistics

\begin{tabular}{|l|c|c|c|c|c|}
\hline Variable & Obs. & Mean & Std. Dev & Min & Max \\
\hline Dependent Variable \\
\hline ROA & 135 & 0.6520 & 0.5771 & 0.0092 & 3.4769 \\
\hline ROE & 135 & 7.8266 & 6.0734 & 0.0906 & 27.73 \\
\hline EPS & 135 & 2182.044 & 2769.872 & 27 & 13635 \\
\hline Independent Variables \\
\hline NPL & 135 & 1.9161 & 1.0038 & 0.3396 & 6.9118 \\
\hline CAR & 135 & 13.3114 & 3.4723 & 1.18 & 24.53 \\
\hline CER & 135 & 53.5174 & 15.4386 & 0.0636 & 90.9638 \\
\hline LDR & 135 & 84.5776 & 14.872 & 37.1866 & 136.7762 \\
\hline LLR & 135 & 1.2148 & 0.3566 & 0.5432 & 2.4490 \\
\hline SIZE & 135 & 11.5856 & 1.2098 & 7.7815 & 14.0878 \\
\hline GDP & 135 & 0.0655 & 0.0040 & 0.0598 & 0.0708 \\
\hline GOV & 135 & 37.886 & 3.7193 & 31.25 & 41.83 \\
\hline
\end{tabular}

Source: Result from the analysis

Table 1 shows the descriptive statistics of the research variables. This research focuses on the sample of 27 commercial banks in the period of $2014-2018$. The analysis indicates numerous information such as the bank's name, the mean values, the median values, the maximum values, the minimum values, and standard deviation. Table 2 describes that bank performance measured by ROA, ROE or EPS. It concludes that banking sector has made a great performance in this period. The highest of ROA, ROE, EPS is $3.47 \%, 27.73 \%$, and 13.635 VND in a given year meanwhile no year to appear the loss of profit.

Regarding bank-specific factors, NPL has an average value of $1.9161 \%$ with the minimum value of $0.3396 \%$ and the maximum value of $6.9118 \%$. The bank's CAR, CER, LDR, LLR have an average value of $13.3114 \%$, $53.5174 \%, 84.5776 \%$, and $1.2148 \%$, respectively, with a major difference. Further, the bank's size has an average value of 11.5856 with a major difference. It is consistent with a major difference in size in the banking sector. Some banks are too larger than other banks. In addition, GDP in Vietnam has drastically fluctuated between 5.25\% and $7.08 \%$ during 2014 - 2018 period, while government ability index has slightly changed between 31.25 and 41.83 .

Table 2: Correlation Coefficents between Variables

\begin{tabular}{|l|c|c|c|c|c|c|c|c|}
\hline Variable & NPL & CAR & CER & LDR & LLR & SIZE & GDP & GOV \\
\hline NPL & 1 & & & & & & & \\
\hline CAR & 0.17 & 1 & & & & & & \\
\hline CER & 0.10 & 0.06 & 1 & & & & & \\
\hline LDR & -0.10 & -0.04 & -0.31 & 1 & & & & \\
\hline LLR & 0.41 & 0.01 & -0.12 & -0.19 & 1 & & & \\
\hline SIZE & -0.19 & -0.37 & -0.13 & -0.09 & 0.14 & 1 & & \\
\hline GDP & -0.15 & -0.12 & -0.14 & 0.31 & -0.09 & 0.12 & 1 & \\
\hline GOV & 0.04 & 0.15 & 0.19 & -0.29 & 0.06 & -0.10 & -0.36 & 1 \\
\hline
\end{tabular}

Source: Result from the analysis

As shown by Gujarati (2004), Tran et al. (2020) multi-collinearity existence between independent variables can be found if correlation coefficient is 0.8 and more, severe multicollinearity could be exactly present when absolute value of pairwise correlations between variables can be relatively high. Table 2 depicts that there is less multicollinearity problem in all cases, correlation coefficients do not have an excess of 0.8 so that the multi-collinearity is not present.

Another possibility, the analysis can check the multi-collinearity based on Variance Inflation Factor (VIF). The result in Table 3 implies that the VIF of independent variables is less than 10. Accordingly, no multi-collinearity problem can be found in the models. 
Table 3: Multi-collinear Test

\begin{tabular}{|l|c|c|}
\hline Variable & VIF & $1 /$ VIF \\
\hline LLP & 1.38 & 0.724691 \\
\hline NPL & 1.37 & 0.731988 \\
\hline LDR & 1.35 & 0.741165 \\
\hline SIZE & 1.31 & 0.764659 \\
\hline GDP & 1.26 & 0.794512 \\
\hline GOV & 1.24 & 0.803926 \\
\hline CER & 1.22 & 0.820402 \\
\hline CAR & 1.20 & 0.833162 \\
\hline Mean VIF & 1.29 & \\
\hline
\end{tabular}

Source: Result from the analysis

\subsection{Discussion of Estimation Models}

The regression methods on the panel data are used in this study including Pooled OLS (Pooled Ordinary Least Square), FEM (fixed-effect model) as well as REM (random-effect model). In agreement with FEM, individual specific effect is significantly related to independent variables, indicating that there is a true effect size which underlines all studies, and differences in observed effects are due to sampling error. In terms of REM, the true effect can vary from study to study. As shown by Wooldridge (2010), pooled OLS is more proper to estimate if the study may choose a different sample for the period of time. Due to inadequate pooled OLS, either FEM or REM could be analyzed in relation to the situation of the same sample of entity in the study. Therefore, the results are investigated by fixed or random effects models that are more possibly exact than using by pooled OLS.

Generally, the effect size can be either higher or lower in this study. Because of the difference in the mixes of participants, implementations of interventions, and other reasons, it further recognizes that there may be different effect sizes underlying different analyses.

Theoretically, Breusch and Pagan Lagrangian multiplier test for random effects can be used to choose either Pooled OLS or REM. Additionally, the results the variance for $u$ is 0 and the p-value is $5 \%$ which means the study cannot reject the null hypothesis and hence select to do a pooled regression. Otherwise is REM. The result is shown in the Table 4 below.

Table 4: Breusch and Pagan Lagrangian for Homoscedasticity

\begin{tabular}{|l|c|c|c|}
\hline & $\begin{array}{c}\text { Model 1 } \\
\text { (ROA) }\end{array}$ & $\begin{array}{c}\text { Model 2 } \\
\text { (ROE) }\end{array}$ & $\begin{array}{c}\text { Model 3 } \\
\text { (EPS) }\end{array}$ \\
\hline Chibar2 (01) & 22.84 & 53.48 & 25.40 \\
\hline Prob > Chibar2 & 0.0000 & 0.0000 & 0.0000 \\
\hline \multicolumn{3}{|r|}{ H0: Constant variance } \\
\hline
\end{tabular}

Source: Result from the analysis

Table 4 shows that the p-value of the Breusch and Pagan Lagrangian multiplier test is 0.0000 . Accordingly, the results indicate that the appropriate model is REM in the significance level of 5\%. In addition, Hausman tests have been used in selecting between FEM and REM. More specifically, the selection between the two models is based on the inter-variance and intra-variability. The select model is FEM if Pro > Chi2, otherwise is REM.

- $\mathrm{H}_{0}$ : The null hypothesis is that the preferred model is random effects

- $\mathrm{H}_{\mathrm{a}}$ : The alternate hypothesis is that the model is fixed effects.

Further, the Hausman test result is given in Table 5.

Table 5: Hausman Test Results

\begin{tabular}{|l|c|c|c|}
\hline & $\begin{array}{c}\text { Model 1 } \\
\text { (ROA) }\end{array}$ & $\begin{array}{c}\text { Model 2 } \\
\text { (ROE) }\end{array}$ & $\begin{array}{c}\text { Model 3 } \\
\text { (EPS) }\end{array}$ \\
\hline Chi2 (8) & 20.83 & 16.66 & 27.28 \\
\hline Prob > Chi2 & 0.0076 & 0.0338 & 0.0006 \\
\hline
\end{tabular}

Source: Result from the analysis 
According to Table 5, the p-value of the Hausman model in three models is between $0.06 \%$ and $3.38 \%$, which is much lower than 0.05, FEM is suggested to be used rather than REM. In conclusion, FEM is the most proper in this study.

\subsection{Results of Econometric Modeling}

In this section, the study will discuss results of the econometric based on the best model of FEM. The results depict in the Table 6 below:

Table 6: Results of Econometric Modeling

\begin{tabular}{|l|c|c|c|}
\hline Variables & $\begin{array}{c}\text { Model 1 } \\
\text { ROA }\end{array}$ & $\begin{array}{c}\text { Model 2 } \\
\text { ROE }\end{array}$ & $\begin{array}{c}\text { Model 3 } \\
\text { EPS }\end{array}$ \\
\hline NPL & $-0.07793(0.216)$ & $-0.79227(0.129)$ & $24.39069(0.932)$ \\
\hline CAR & $-0.00511(0.783)$ & $-0.00633(0.967)$ & $-33.94804(0.690)$ \\
\hline CER & $-0.00340(0.322)$ & $-0.02681(0.346)$ & $-0.47743(0.976)$ \\
\hline LDR & $0.11417(0.014)^{* *}$ & $0.12461(0.001)^{* * *}$ & $40.68747(0.056)^{*}$ \\
\hline LLR & $0.07892(0.628)$ & $0.22575(0.867)$ & $-901.3454(0.228)$ \\
\hline SIZE & $-0.40229(0.000)^{* * *}$ & $0.62472(0.355)$ & $-789.9081(0.036)$ \\
\hline GDP & $15.55669(0.133)$ & $133.8563(0.119)$ & $25775.36(0.585)$ \\
\hline GOV & $-0.00292(0.787)$ & $0.00133(0.988)$ & $-99.09875(0.047)^{* *}$ \\
\hline C & $3.74248(0.005)^{* * *}$ & $-16.00796(0.145)$ & $11483.78(0.060)^{* *}$ \\
\hline
\end{tabular}

Notes: *, **, and *** indicate significance level of $10 \%, 5 \%$ and $1 \%$

Source: Result from the analysis

\subsubsection{Autocorrelation Test}

Based on the Wooldridge test, we have:

- The Null hypothesis H0: no first order autocorrelation

- The Alternative hypothesis Ha: existence of an autocorrelation

It reports that autocorrelation test used for null hypothesis as "no first order autocorrelation", Table 7 depicts that the p-value of the FEM is very close to zero. They are all less than 0.05 or 0.10 so that null hypothesis could be rejected, indicating that there is an autocorrelation between variables in the three models.

Table 7: Wooldridge Test for Autocorrelation in Panel Data

\begin{tabular}{|l|c|c|c|}
\hline & Model 1 & Model 2 & Model 3 \\
\hline $\mathrm{F}(1,26)$ & 5.109 & 3.675 & 24.304 \\
\hline Prob > F & 0.0324 & 0.0663 & 0.0000 \\
\hline
\end{tabular}

H0: no first order autocorrelation

Source: Wooldridge test - STATA 15

\subsubsection{Heteroscedasticity Test}

In terms of heteroscedasticity, the White test could be performed. In the theory, if the test result with p-value is 0.05 and less, heteroscedasticity can be found at the significant level at 5 percent. Table 8 reports that the test result with p-value is 0.0000 , indicating that the model has heteroscedasticity problem.

Table 8: Modified Wald test for Groupwise Heteroskedasticity in Fixed Effect Regression Model

\begin{tabular}{|c|c|c|c|}
\hline & Model 1 & Model 2 & Model 3 \\
\hline chi2 (27) & $2.5 \mathrm{e}+05$ & 3302.34 & 11985.61 \\
\hline Prob > chi2 & 0.0000 & 0.0000 & 0.0000 \\
\hline \multicolumn{3}{|c|}{ H0: sigma(i)^2 = sigma^2 for all i } \\
\hline
\end{tabular}


Table 9: Results of Econometric Modeling (Correction)

\begin{tabular}{|l|c|c|c|}
\hline Variables & Model 1 & Model 2 & Model 3 \\
& ROA & ROE & EPS \\
\hline NPL & -0.07793 & -0.79227 & 24.3906 \\
& $(0.037)^{* *}$ & $(0.079)^{*}$ & $(0.923)$ \\
\hline CAR & -0.00511 & -0.00633 & -33.9480 \\
& $(0.732)$ & $(0.962)$ & $(0.588)$ \\
\hline CER & -0.00340 & -0.02681 & -0.47743 \\
& $(0.424)$ & $(0.510)$ & $(0.976)$ \\
\hline LDR & 0.01141 & 0.12461 & 40.68747 \\
& $(0.010)^{*}$ & $(0.001)^{* * *}$ & $(0.056)^{*}$ \\
\hline LLR & 0.0789205 & 0.225759 & -901.3454 \\
& $(0.642)$ & $(0.901)$ & $(0.098)^{*}$ \\
\hline SIZE & -0.40229 & 0.62472 & -789.9081 \\
& $(0.188)$ & $(0.313)$ & $(0.121)$ \\
\hline GDP & 15.55669 & 133.8563 & 25775.36 \\
& $(0.230)$ & $(0.109)$ & $(0.465)$ \\
\hline GOV & -0.00292 & 0.00133 & -99.0987 \\
& $(0.780)$ & $(0.985)$ & $(0.071)^{*}$ \\
\hline C & 3.74248 & -16.0079 & 11483.78 \\
& $(0.322)$ & $(0.172)$ & $(0.152)$ \\
\hline
\end{tabular}

Notes: *, **, and $* * *$ indicate significance level of $10 \%, 5 \%$ and $1 \%$

Source: Result from the analysis

\section{Discussions}

Regarding the estimation results in the Table 9, our analysis shows the impact of control of corruption, bankspecific factors and efficiency in an insight from banking sector of Vietnam as follows:

\section{Government Ability}

In three models, when bank performance measured by EPS, the regression coefficient of this variable is negative and statistically significant at the level of 10 percent. To be precise, the impact of control of corruption on efficiency in the banking system is statistically significant and negative. A higher level in control of corruption, on average, will predominantly decrease the profitability of a bank. This result is associated with some empirical findings of Guo et al. (2019) in China but this does not support for our theoretical literature. In fact, although the government ability of Vietnam has changed at a downtrend in the years of 2014 - 2018 (see Figure 3), but the bank performance has been increased during this period. This surprising result can be explained that Vietnam has greatly made some significant efforts in its fight against corruption since 2016. In addition, the corruption campaign has focused on positions of financial influence, and a variety of political leaders in the local and central government. The country's anti-corruption has been continued to expand at a large scope and economic areas.

\section{Bank-specific Factors}

In the three models, the result shows that the coefficient of NPL is negative and significant. It is better to say that the impact of the NPL on the bank efficiency is actually negative. It depicts that a bank with a higher of nonperforming loan will negatively affect its performance. This finding is associated with Ekinci \& Poyraz (2019) in the study based on bank-level data for 26 Turkish banks in the period of $2005-2017$.

Regarding LDR, this variable of loan-to-deposit ratio (LDR) used to evaluate the liquidity by comparing the total loans to its deposits in a bank in the same period. The results show that LDR has a positive effect on the probability of a bank, like the finding of Sohel Azad et al. (2019) in a group of twenty countries. It is in line with the theoretical arguments that a bank with a higher level of LDR is associated with a higher level of the probability of a bank.

Regarding LLR, the regression results show that LLR has a negative impact on the profitability of banks listed Ho Chi Minh City Stock Exchange (HOSE) and Hanoi Stock Exchange (HNX). Importantly, increasing in loan loss reserves will significantly reduce the profitability of a bank. It indicates that a bank with a greater risk in operation will negatively impact on its efficiency. This observation is similar to Mustafa et al. (2012) assessing in banking 
sector in Pakistan. In general, a bank with less loan loss provision are recognized to be more safety and such a huge advantage can be expressed a greater profitability.

Bank-specific factors as CAR, CER, and SIZE, the results denotes that these variables are not statistically significant at $10 \%$ level of significance. It depicts that these results do not support the hypothesis as in the study of

Furthermore, the effect of economic growth on efficiency in the banking sector is positive but insignificant. More specifically, an increase in economic performance will not promote the profitability of a bank in the case of Vietnam. This finding is not in relation to Rashid \& Jabeen (2016). However, Vietnam needs to modernize economic institutions so as the economy has developed sustainably in the long run.

\section{Conclusion and Implications}

This research employs an balanced panel data to investigate the impact of government ability, bank-specific factors and efficiency in Vietnamese banks in the period 2014 -2018. The secondary data were collected from in Ho Chi Minh City Stock Exchange (HOSE) and Hanoi Stock Exchange (HNX) and included both state-owned commercial banks and private joint-stock commercial banks.

Main factors that can significantly impact the profitability of a bank are non-performing loan, loan-to-deposit ratio, loan loss reserves and government ability. Empirical results describe that a greater level in government ability will negatively affect the profitability of a bank. Further, a bank with a higher loan-to-deposit ratio can positively impact on the probability of a bank. In contrast to the risk, a bank with a greater risk as well as non-performing loan in operation will negatively impact on its efficiency. Regarding economic performance, economic growth insignificantly affects bank efficiency but this effect is positive. Thus, Vietnam should focus on economic performance to inspire bank efficiency.

This study has important implications for future researchers. Firstly, the study has mostly focused on bankspecific factors, in particular government ability and its impact on the banking sector performance, it is further indicated that the study should focus on other factors, in particular in macroeconomic factors and the competitive environment between foreign-owned banks and local banks. Secondly, the most important factor used in this study is government ability that could affect the bank efficiency in the case of Vietnam. Further discussed on this factor, the study needs to undertake meta-analyses in order to contribute for the hypothesis.

\section{References}

1. Brandao-Marques, L., Correa, R., Sapriza, H. (2020). Government support, regulation, and risk taking in the banking sector. Journal of Banking \& Finance, 112, 105284.

2. Ekinci, R. \& Poyraz, G. (2019). The Effect of Credit Risk on Financial Performance of Deposit Banks in Turkey. Procedia Computer Science, 158, 979-987.

3. Fang, J., Lau, C.K.M., Lu, Z., Tan, Y., Zhang, H. (2019). Bank performance in China: A Perspective from Bank efficiency, risk-taking and market competition. Pacific-Basin Finance Journal, 56, 290-309.

4. Gujarati, D. (2004) Basic Econometrics. 4th Edition, McGraw-Hill Companies, New York.

5. Guo, F., Zou, B., Zhang, X., Bo, Q., Li, K. (2019). Financial slack and firm performance of SMMEs in China: Moderating effects of government subsidies and market-supporting institutions. International Journal of Production Economics. 107530.

6. Ho, P.H., Chen, H.K., Lin, C.Y., Chi, C.W. (2016). Does monitoring by the media improve the performance of government banks? Journal of Financial Stability, 22, 76-87.

7. Martins, A., Serra, A.P., Stevenson, S. (2019). Determinants of real estate bank profitability. Research in International Business and Finance, 49, 282-300.

8. Mustafa, A.R., Ansari, R.H., Younis, M.U. (2012). Does the loan loss provision affect the banking profitability in the case of Pakistan. Asian Economic and Financial Review, 2(7), 772-783.

9. Nguyen, V. (2020). Human capital, capital structure choice and firm profitability in developing countries: An empirical study in Vietnam. Accounting. 6(2), 127-136.

10. Nguyen, V.C. \& Do, T.T. (2020). Impact of exchange rate shocks, inward FDI and import on export performance: a cointegration analysis. Journal of Asian Finance, Economics and Business, 7(4), 163-171.

11. Rashid, A., and Jabeen, S. (2016). Analyzing performance determinants: Conventional versus Islamic Banks in Pakistan. Borsa Istanbul Review, 16(2), 92-107.

12. Sohel Azad, A., Azmat, S., Hayat, A. (2019). What determines the profitability of Islamic banks: Lending or fee? International Review of Economics \& Finance, 2019. 
13. Tran, T.N., Nguyen, T.T., Nguyen, V.C., Vu, T.T.H. (2020). Energy Consumption, Economic Growth and Trade Balance in East Asia: A Panel Data Approach. International Journal of Energy Economics and Policy, 10(4), 1-7.

14. Nguyen, V.C. \& Tran, V.D. (2013). Enhancing of the quality of public policy promulgation in Vietnam. Journal of State and Law, 371, 28-35.

15. Van, N.C. (2020). Energy consumption, income, trading openness, and environmental pollution: Testing environmental Kuznets curve hypothesis. Journal of Southwest Jiaotong University, 55(1), 1-10.

16. Wooldridge, J. (2010). Econometric Analysis of Cross Section and Panel Data. MIT Press. 